\title{
Relationship between the Influence of Others' Opinions on Taste during Co-Eating and the Empathy of Individuals
}

\author{
Hiromi Inaba*, Genki Sakauchi, Shiho Tsuchida, Momoko Asada, Naoto Sato, Kasumi Suzuki, \\ Kenichi Shibuya
}

Health Sciences, Health and Nutrition Department, Niigata University of Health and Welfare, Niigata, Japan

Email: ‘inaba@nuhw.ac.jp

How to cite this paper: Inaba, H., Sakauchi, G., Tsuchida, S., Asada, M., Sato, N., Suzuki, K. and Shibuya, K. (2018) Relationship between the Influence of Others' Opinions on Taste during Co-Eating and the Empathy of Individuals. Journal of Behavioral and Brain Science, 8, 197-206. https://doi.org/10.4236/jbbs.2018.84013

Received: March 26, 2018

Accepted: April 23, 2018

Published: April 26, 2018

Copyright (c) 2018 by authors and Scientific Research Publishing Inc. This work is licensed under the Creative Commons Attribution International License (CC BY 4.0).

http://creativecommons.org/licenses/by/4.0/

Open Access

\begin{abstract}
The purpose of this study was to investigate whether the opinions of people eating together affect the taste of the foods they eat. In addition, if the opinions of others influence taste for one of the people eating with them, are the others' opinions related to the empathy of individuals? Finally, this study was also intended to consider whether the taste threshold changes depending on the opinions of others. Twelve healthy young women (aged $18.4 \pm 0.8$ years; mean \pm SD) participated in the present study. The participants tasted bread under three conditions: 1) quiet condition: a participant ate with three quiet persons, 2) positive condition: a participant ate with three persons who were talking favorably about taste, and 3) negative condition: a participant ate with three persons who were talking negatively about the taste. The electrical taste threshold was tested before and after tasting the bread, and a visual analog scale (VAS) was completed immediately after the tasting. Before the first trial, participants were asked to complete the Interpersonal Reactive Index (IRI). In the positive condition, the taste score increased significantly compared with the negative condition. There was no significant relationship between taste and empathic concern. To our knowledge, taste changed according to the comments of other people who were eating together. However, the change in taste due to the other's speech was not related to the individual's empathy. The results of the present study suggest that people experience food as delicious when others eating with them comment about the food being "delicious," and this tendency did not depend on individuals' empathy.
\end{abstract}

\section{Keywords}

Social Facilitation, Electrical Taste Threshold, Taste, GLMM 


\section{Introduction}

Eating is important as a means of communication, in addition to maintaining life. It is well known that people's taste experiences are improved when another individual is present, in comparison to eating alone [1]. This promotion effect of eating with another person is called the "social facilitation of eating," which refers not only to increases in the amount of food intake, but also to taste as well [2] [3] [4] [5]. The number of people present was positively correlated with meal size [6]. One explanation for this phenomenon concerns the positive mood effect derived from people's active communication while eating with others and trying to establish a good relationship [7]. Thus, as eating with others brings about a positive change in mood, this positive change might lead us to the social facilitation of eating [8] [9]. We eat with someone to be sociable. However, one of the reasons we co-eat is a desire to eat more than when eating alone [10]. We eat more when we co-eat with close friends and family than when eating with other people [9] [11]. In this way, there are many positive reports concerning the "social facilitation of eating" by co-eating.

There are many reports that taste is more delicious when co-eating than when eating alone [5]. However, it is unclear what affects taste during co-eating. Kihlberg and Caporale reported that the taste of food changes with advance information on food [12] [13]. Furthermore, Siegrist reported that delivering preliminary information on delicious or bad food significantly affected the taste, but also indicated that the taste did not change when information was provided after tasting [14]. If taste changes according to advance information, the magnitude of change may be related to individuals' empathy. Moreover, while there are reports that taste changes according to advance information, there is no report on changes in the taste threshold.

Therefore, we decided to pay attention to the content of opinions of people who are eating together, which were not stated in advance. The purpose of this study was to examine the influence of others' opinions on taste. In addition, if the opinion of others influences taste, is it related to individuals' empathy individuals? Finally, the study also intended to consider whether the taste threshold changes depending on others' opinions.

\section{Participants and Methods}

\subsection{Participants}

Twelve nonsmoking, young healthy women (aged 18.4 \pm 0.8 years, BMI: $20.2 \pm$ 1.7; mean \pm SD) participated in the present study. They had no food allergies. The study protocol was approved by the Ethics Committee of Niigata University of Health and Welfare (No. 17834-170608). Each participant provided written informed consent after the experimenter's explanation of the aims and methodology of the study.

\subsection{Tasting}

Participants arrived after having no food in the two hours prior to testing, and 
were instructed to sit on a chair behind a rectangular table $(150 \times 80 \mathrm{~cm})$. Before the tasting, participants were asked to try tasting new bread that was being developed. A $10 \mathrm{~cm} \times 5 \mathrm{~cm}$ piece of white bread without the heel, (Choujuku, Sthikishima Bread Co., LTD., Aichi, Japan) was placed on a white paper dish. Participants tasted the bread under three conditions in randomized order, at least three days apart. In condition 1, the participant ate with three strangers who ate quietly (quiet condition). In condition 2, the participant ate with three strangers who spoke positively about the white bread (positive condition). In condition 3, the participant ate with three strangers who spoke negatively about the white bread (negative condition). In all three conditions, the strangers never spoke to the participant. In the three conditions, $15 \mathrm{~g}$ of white bread was tasted. The electrical taste threshold was measured before and immediately after tasting the bread [15]. Participants washed out their mouth with ion-exchanged water before and after tasting. A physical condition and hunger scale was completed each time. Each participant was required to rate the deliciousness, texture, taste palatability, intensity of taste, and appetite using a visual analog scale (VAS) with scores between 0 and 10, and the order of the conditions was randomized for each participant, (Figure 1).

\subsection{Apparatus}

Electrical taste thresholds were measured with an electric stimulator meter (AO-A 41,000, Applied Office, Tokyo, Japan). To test the threshold, the tongue median groove fungiform papilla (chorda innervation dominant region) was used as the contact point of the electrode (stainless steel, 5-mm diameter). The stimulation time was set to two seconds. The electric flow rate was gradually decreased from $32 \mu \mathrm{A}$, and the participants indicated when they felt stimulation. To exclude visual information, participants wore eye masks during the tasting. The experiment was conducted over a total of four days.

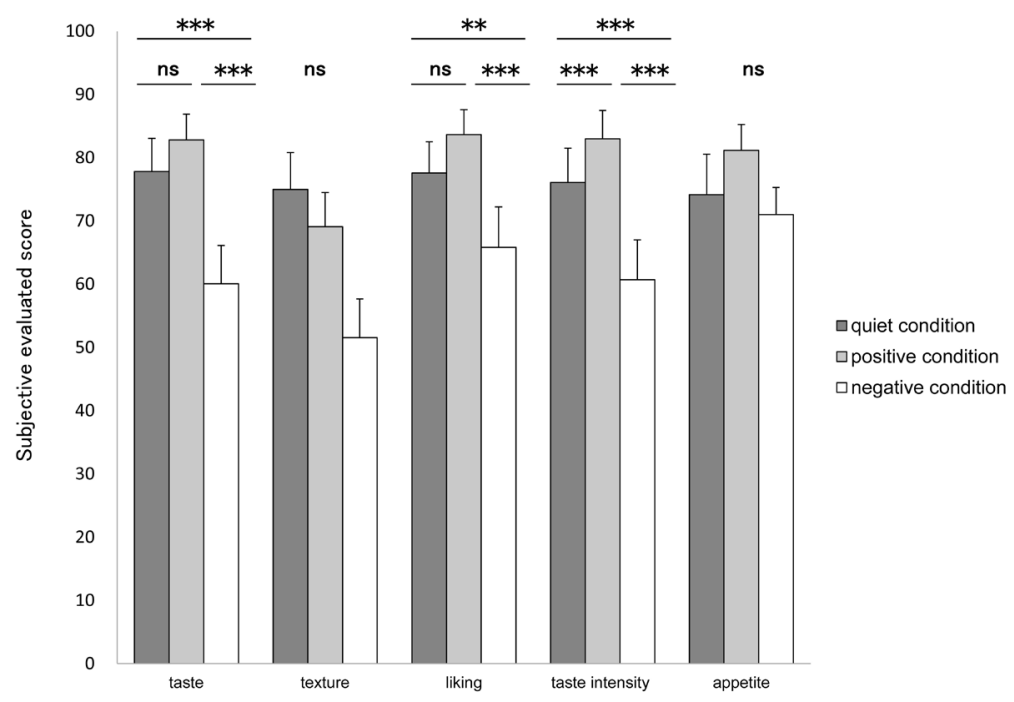

Figure 1. Visual analog scale (VAS). 


\subsection{Measures}

After the participants agreed to participate in this experiment, they were asked to complete the Interpersonal Reactive Index (IRI, with four subscales: perspective-taking, fantasy, empathic concern, and empathic distress) [16]. Immediately after the tasting, the participants' indicated their responses on a $10-\mathrm{cm}$ line (VAS). The short questionnaire contained 5 items that measured deliciousness, intensity of taste, texture, taste palatability, and appetite.

\subsection{Data Analysis}

Generalized linear mixed models (GLMMs) were used to determine the impact of various factors. One of the merits of GLMMs is that they can manage nested data. Additionally, they can incorporate not only fixed effects, but also random effects, such as different response tendencies among the participants. In fact, GLMMs have been used in recent eye-tracking studies [17] [18] [19]. For the obtained data, we used the lmer function of the lmer Test package available in $\mathrm{R}$ (R, Version 3.2.4, Development Core Team, 2011).

In the GLMM analysis, we set "Condition" (positive, quiet, negative), "VAS" (delicious, taste palatability, intensity of taste, texture, appetite), and "electrical taste threshold" as fixed effects, and participant ID, physical condition, hunger level, temperature, and humidity as variable effects. We performed an analysis of variance (ANOVA) using the data acquired from the GLMM. We used the Kenward-Roger approximation of the degrees of freedom for this analysis. Then for the multiple comparisons, we calculated differences of least square means and confidence intervals for the fixed factors of the linear mixed-effects model. For all analyses, $p<0.05$ was considered statistically significant.

\section{Results}

The physical condition ( 1 to 5 , bad to good) and hunger range (1 to 5, bad to good) are shown in Table 1. There was no significant difference in physical condition between the three conditions. The hunger values differed significantly between positive and negative conditions ( $p<0.001,95 \%$ CI-0.665 to -0.208 ).

The scores for taste, intensity of taste, texture, taste palatability and appetite are shown in Figure 2. The mean taste score in the negative condition (59.5 \pm 4.7) was significantly lower than the scores in the quiet $(76.4 \pm 4.5)$ and positive conditions $(81.0 \pm 4.5)(p<0.001,95 \%$ CI 66.7 to 86.0 , 95\% CI 71.4 to 90.7 , respectively). On the other hand, there were no differences in appetite among the three conditions.

\section{Interpersonal Reactive Index (IRI)}

The scores for the IRI (perspective taking, fantasy, empathic concern, and personal distress) are shown in Table 2. The relationships between VAS values and IRI scores are shown in Table 3. There were no relationships between deliciousness and empathic concern, perspective-taking, fantasy, and personal distress 
Table 1. Physical condition.

\begin{tabular}{ccccccc}
\hline Condition & \multicolumn{3}{c}{ Physical condition } & \multicolumn{3}{c}{ Hunger level } \\
\hline quiet & 3.9 & \pm & 0.4 & 4.4 & \pm & 0.1 \\
Positive & 4.2 & \pm & 0.2 & 4.5 & \pm & 0.2 \\
Negative & 3.7 & \pm & 0.4 & 3.8 & \pm & 0.4 \\
\hline
\end{tabular}

Mean $\pm \mathrm{SD}, \mathrm{n}=12$

Table 2. Interpersonal reactive index score.

\begin{tabular}{cccc}
\hline Prespective taking & 35.1 & \pm & 5.8 \\
Fantasya & 31.6 & \pm & 7.8 \\
Empatic concern & 32.3 & \pm & 4.8 \\
Personal ditress & 34.3 & \pm & 4.6 \\
\hline
\end{tabular}

Mean \pm SD, $\mathrm{n}=12$.

Table 3. VAS and IRI score.

\begin{tabular}{ccccc}
\hline \multirow{2}{*}{$\begin{array}{c}\text { Subject } \\
\text { number }\end{array}$} & IRI score & \multicolumn{3}{c}{ Condition } \\
\cline { 3 - 5 } 1 & & Quiet & Positive & Negative \\
\hline 2 & 41 & 82 & 49 & 62 \\
3 & 35 & 74 & 79 & 61 \\
4 & 39 & 76 & 79 & $-*)$ \\
5 & 34 & 42 & 83 & 42 \\
6 & 29 & 66 & 67 & 77 \\
7 & 26 & 73 & 92 & 52 \\
8 & 34 & 100 & 78 & 82 \\
9 & 32 & 96 & 99 & 90 \\
10 & 33 & 91 & 92 & 72 \\
11 & 32 & 96 & 97 & 60 \\
12 & 24 & 51 & 98 & 22 \\
\hline & 29 & 87 & 91 & 42 \\
\hline
\end{tabular}

$\left.\mathrm{n}=12,{ }^{\star}\right)$ : Experiment conditions for preference study were not prepared.

Please check where you find it most appropriate.

ex : not like

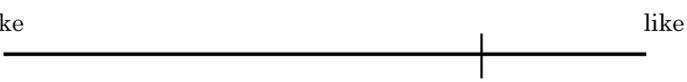

do not feel strongly

Feel strongly
(1) taste
(2) intensity of taste
(3) texture
(4) taste palatability
(5) appetite

Figure 2. Results of sensory test. 
$(p<0.05)$. On the other hand, texture had a significant relationship with perspective-taking, and taste palatability was significantly related with perspective-taking and fantasy. The appetite value had a significant relationship with fantasy.

The electrical taste threshold did not differ significantly among the three conditions (Table 4$)(p=0.556,95 \% \mathrm{Cl}-0.307$ to 6.78$)$, nor between pre- and post-tasting ( $p=0.371,95 \% \mathrm{Cl}-2.31$ to 6.08$)$.

\section{Discussion}

The purpose of this study was to investigate whether the opinions of people eating together affect the taste of the foods they eat. In addition if they change, whether the change is related to an individual's empathy, furthermore, the study endeavored to clarify the influence of remarks by others on changes to the taste threshold. The most important finding of our study was that taste changes according to the comments of other people who are eating together. However, it turns out that the change in taste due to remarks by others was not related to the individual's empathy. In addition, the electric taste threshold is not change depending on the remarks by others.

There are many reports that the taste of food is decreased when eating alone [5]. However, it is unclear what affects taste during co-eating. Therefore, we focused on the content of opinions during co-eating. Others' comments at the time of co-eating were related to significantly higher scores for taste, texture, and taste preference in the positive comment condition compared to the negative condition (Figure 1). There are many reports that taste assessment changes according to prior information on food. Kihlberg found that taste assessment was higher when information on organic bread was given in advance, compared to general bread [12], and Caporale and others examined that the taste evaluation will change by telling information on the beer manufacturing technology before the beer tasting [13]. Fouremoer, Siegrist indicated that providing preliminary information, such as whether food is delicious or bad, significantly influences taste assessment, but taste assessment did not change when information was provided after the taste survey [14]. In this study, the positive or negative information was provided during tasting rather than in advance. Due to the fact that the taste assessment differed significantly under these conditions, it is presumed that the conversation during the tasting survey has the same influence as the

Table 4. Electical taste thresholde.

\begin{tabular}{ccccccc}
\hline Condition & \multicolumn{3}{c}{ Pre } & \multicolumn{3}{c}{ Post } \\
\hline Quiet & 16.3 & \pm & 4.0 & 18.1 & \pm & 3.1 \\
Positive & 14.2 & \pm & 2.6 & 15.9 & \pm & 3.2 \\
Negative & 17.0 & \pm & 4.7 & 18.3 & \pm & 4.6 \\
\hline
\end{tabular}

$\mathrm{n}=9$, one person who did not meet the condition and two who did not measure the threshold value are excluded. 
information provided in advance, and the content of conversation during eating influences the quality of the meal.

In this study, since opinions were limited to evaluated foods, the evaluation results of the participants may have been biased against taste. When another person remarks regarding the atmosphere of a place, such as "fun" or "troublesome," the evaluation of the other person's speech and taste has a different inference from that in the present study. In addition, future study should examine the condition of co-eating, not with a stranger, but with close friends.

The second hypothesis was rejected, although the degree of influence was related to the empathic consideration scale when the opinions of co-eaters affected the taste rating of the participant. Factors that affect empathy include genetic factors such as gender and age, and socio-cultural factors, such as education and belief, and environmental factors [20]. In this research, we used the Japanese version [21] of the Interpersonal Reactivity Index [16] [22] that integrates emotional and cognitive aspects and captures them in a multidimensional structure. The IRI's empathic consideration scale is known to be higher for women than for men [23]. In addition, young women, who typically have a low threshold [24] [25], were used as participants to measure taste thresholds, but further studies are needed to determine whether similar results can be obtained when targeting older women or men.

In this experiment, the content of the remarks by others who eat together did not affect the taste threshold. Individual differences in taste thresholds exist and are suspected to influence daily food intake and, consequently, body weight-although concrete evidence of this is still lacking [26] [27]. The electric taste threshold of this experiment was $16.4 \pm 11.4 \mu \mathrm{A}$ (mean \pm standard deviation): the lowest value was $3.2 \mu \mathrm{A}$, the highest value was $40.0 \mu \mathrm{A}$, and the normal value was $40.0 \mu \mathrm{A}$ or less [28]. Various factors influencing taste have been reported such as olfaction, hearing, tactility, aging, and stress [27] [29], although visual factors have been reported as having the strongest effect on the taste of food and meals [30] [31]. Petra Platte and colleagues report that after seeing negative or positive images, the intensity of sweetness and acidity changes [32]. It is assumed that the change of the threshold value was not detected because the content of the remarks, not the visual stimulus, was changed and the measurement of taste comprised the electric taste threshold instead of the five basic tastes. It was suggested that the remarks of others only affected the taste without affecting the taste threshold. Further examination is needed as to whether the taste threshold changes due to factors other than the visual influences such as the contents of the speech.

de Castro et al. reported that the social facilitation of eating does not only increase food intake, but also improves taste [2] [3] [4] [5]. Fourthermore, researchers have reported that food intake increased with co-feeding [9]. Clendenen reported that the amount of energy consumed increased when people dined with friends rather than eating together with other people, paying attention to 
the person they eat together. As a factor to increase intake amount, there is a decrease in the consciousness of how much you are eating and how full you are [12], and it is said that it makes you feel happy because you will not be wary of surroundings [10]. In this study, since the taste survey was conducted after completing half of a piece of bread, the amount of food consumption could not be compared and appetite was used as an indicator instead. If we could adopt a method of actually eating as much as desired in the experimental conditions, a change in food intake may be observed depending on the condition.

From the findings of the experiments conducted in the present study, it became clear that others' comments during co-eating influence taste. Moreover, no significant correlations were found between the change in taste ratings and scores on the empathic consideration scale. Furthermore, it became clear that the electric taste threshold did not change significantly according to the remarks by others. It is recommended not to be alone but to eat with someone, but it was thought that it is an important factor to eat delicious contents of conversation when eating. Further studies are needed to understand the mechanisms by which the taste and intake of a meal is promoted by the food environment, including cooking and conversation.

\section{Conclusion}

The most important finding of our study was that taste changes according to the comments of other people who are eating together, but it turns out that the change in taste due to the others' remarks is not related to the individual's empathy. In addition, the electric taste threshold does not change depending on the opinions of others. The results of the present study suggest that people find the food or meal to be delicious when other people with whom they are eating make "delicious" comments, and this trend is not changed by empathic concern.

\section{Declaration of Conflicting Interests}

The authors declared no potential conflicts of interest with respect to the research authorship, and/or publication of this article.

\section{Acknowledgements}

We would like to thank Dr. Shibuya of Niigata University of Health and Welfare, for his assistance with the research design.

We would like to thank Editage (https://www.editage.jp/) for English language editing.

\section{References}

[1] Bellisle, F. and Dalix, M. (2001) Cognitive Restraint Can Be Offset by Distraction, Leading to Increased Meal Intake in Women. American Journal of Clinical Nutrition, 74, 197-200. https://doi.org/10.1093/ajcn/74.2.197

[2] de Castro, J.M. (1991) Social Facilitation of the Spontaneous Meal Size Human Succors on Both Weekdays and Weekends. Physiology \& Behavior, 491, 1289-1291. 
https://doi.org/10.1016/0031-9384(91)90365-U

[3] de Castro, J.M., Brewer, E.M., Elmore, D.K. and Orozco, S. (1991) Social Facilitation of the Spontaneous Meal Size of Humans Is Independent of Time, Place, Alcohol, or Snacks. Appetite, 15, 89-101. https://doi.org/10.1016/0195-6663(90)90042-7

[4] de Castro, J.M. (1995) Social Facilitation of Food Intake in Humans. Appetite, 24, 260. https://doi.org/10.1016/S0195-6663(95)99835-7

[5] Herman, C.P. (2015) The Social Facilitation of Eating: A Review. Appetite, 86, 61-73. https://doi.org/10.1016/j.appet.2014.09.016

[6] de Castro, J.M. and de Castro, E.S. (1989) Spontaneous Meal Patterns of Humans: Influence of the Presence of Other People. American Journal of Clinical Nutrition, 50, 237-247. https://doi.org/10.1093/ajcn/50.2.237

[7] Baumeister, R.F. and Leary, M.R. (1995) The Need to Belong: Desire for Interpersonal Attachments as a Fundamental Human Motivation. Psychological Bulletin, 117, 497-529. https://doi.org/10.1037/0033-2909.117.3.497

[8] Hetherington, M.M. (2007) Cues to Overeat: Psychological Factors Influencing Overconsumption. Proceedings of the Nutrition Society, 66, 113-123. https://doi.org/10.1017/S0029665107005344

[9] Sommer, W., Stürmer, B., Shmuilovich, O., Martin-Loeches, M. and Schacht, A. (2013) How about Lunch? Consequences of the Meal Context on Cognition and Emotion. PLoS ONE, 8, e70314. https://doi.org/10.1371/journal.pone.0070314

[10] Herman, C.P. (2017) The Social Facilitation of Eating or the Facilitation of Social Eating? Journal of Eating Disorders, 27, 5-16. https://doi.org/10.1186/s40337-017-0146-2

[11] Clendenen, V.I., Herman, C.P. and Polivy, J. (1994) Social Facilitation of Eating among Friends and Strangers. Appetite, 23, 1-13.

https://doi.org/10.1006/appe.1994.1030

[12] Kihlberg, I., Johansson, L., Langsrud, O. and Risvik, E. (2005) Effects of Information on Liking of Bread. Food Quality and Preference, 16, 25-35.

https://doi.org/10.1016/j.foodqual.2003.12.005

[13] Caporale, G. and Monteleone, E. (2004) Influence of Information about Manufacturing Process on Beer Acceptability. Food Quality and Preference, 15, 271-278. https://doi.org/10.1016/S0950-3293(03)00067-3

[14] Siegrist, M. and Cousin, M.E. (2009) Expectations Influence Sensory Experience in a Wine Tasting. Appetite, 52, 762-765. https://doi.org/10.1016/j.appet.2009.02.002

[15] Lobb, B., Elliffe, D.M. and Stillman, J.A. (2000) Reliability of Electrogustometry for the Estimation of Taste Thresholds. Clinical Otolaryngology, 25, 531-534. https://doi.org/10.1046/j.1365-2273.2000.00392.x

[16] Davis, H.M. (1983) Measuring Individual Dereferences in Empathy: Evidence for a Multidimensional Approach. Journal of Personality and Social Psychology, 44, 113-126. https://doi.org/10.1037/0022-3514.44.1.113

[17] Cornelissen, P.L., Hancock, P.J.B., Kiviniemi, V., George, H.R. and Tovée, M.J. (2009) Patterns of Eye Movements When Male and Female Observers Judge Female Attractiveness, Body Fat And waist-to-Hip Ratio. Evol Hum Behav, 30, 417-428.

[18] Nuthmann, A. and Einhäuser, W. (2015) A New Approach to Modeling the Influence of Image Features on Fixation Selection in Scenes. Annals of the New York Academy of Sciences, 1339, 82-96. https://doi.org/10.1111/nyas.12705

[19] Stoll, J., Thrun, M., Nuthmann, A. and Einhäuser, W. (2015) Overt Attention in Natural Scenes: Objects Dominate Features. Vision Research, 107, 36-48. 
https://doi.org/10.1016/j.visres.2014.11.006

[20] Eisenberg, N. and Miller, P.A. (1987) The Relation of Empathy to Prosocial and Related Behaviors. Psychological Bulletin, 101, 91-119. https://doi.org/10.1037/0033-2909.101.1.91

[21] Sakurai, S. (1988) The Relationship between Empathy and Helping Behavior in College Students. Bulletin of Nara University of Education, Cultural and Social Science, 37, 149-154.

[22] Davis, M.H. (1980) A Multidimensional Approach to Individual Differences in Empathy. JSAS Catalogue of Selected Documents in Psychology, 10, 85.

[23] Bratek, A., Bulska, W., Born, M. and Seweryn, M. (2015) Empathy among Physicians, Medical Students and Candidates. Psychiatria Danubina, 27, S48-S52.

[24] Alfred, C. and Coats, M.D. (1974) Effects of Age, Sex, and Smoking on Electrical Taste Threshold. Annals of Otology, Rhinology \& Laryngology, 83, 365-366. https://doi.org/10.1177/000348947408300312

[25] Lee, J.W., Son, H.J., Shin, S.H., Rhyu, M.R., Kim, J.Y. and Ye, M.K. (2014) Differences in Taste Thresholds According to Sex and Age Groups in Korean. Korean Journal of Otorhinolaryngology_Head and Neck Surgery, 57, 692-697. https://doi.org/10.3342/kjorl-hns.2014.57.10.692

[26] Donaldson, L.F., Bennett, L., Bai, S. and Melichar, J.K. (2009) Taste and Weight: Is There a Link? The American Journal of Clinical Nutrition, 90, 800s-803s. https://doi.org/10.3945/ajen.2009.27462Q

[27] Ileri-Gurel, E., Pehlivanoglu, B. and Doga, M. (2013) Effect of Acute Stress on Taste Perception: In Relation with Baseline Anxiety Level and Body Weight. Chemical Senses, 38, 27-34. https://doi.org/10.1093/chemse/bjs075

[28] Grant, R., Ferguson, M.M., Strang, R., Turner, J.W. and Bone, I. (1987) Evoked Taste Thresholds in a Normal Population and the Application of Electorogustometry to Trigeminal Nerve Disease. Journal of Neurology, Neurosurgery, and Psychiatry, 50, 12-21. https://doi.org/10.1136/jnnp.50.1.12

[29] Pereira, L.J. and van der Bilt, A. (2016) The Influence of Oral Processing, Food Perception and Social Aspects on Food Consumption: A Review. Journal of Oral Rehabilitation, 143, 630-648. https://doi.org/10.1111/joor.12395

[30] Birren, F. (1963) Color and Human Appetite. Food Technology, 17, 553-555.

[31] Szczesniak, A.S. and Kleyn, D.H. (1963) Consumer Awareness of Texture and Other Food Attributes. Food Technology, 17, 74-77.

[32] Platte, P., Herbert, C., Pauli, P. and Breslin, P.A.S. (2013) Oral Perceptions of Fat and Taste Stimuli Are Modulated by Affect and Mood Induction. PLOS ONE, 8 , e65006. https://doi.org/10.1371/journal.pone.0065006 